\title{
The Internal Audit Dilemma - The Impact of Executive Directors versus Audit Committees on Internal Auditing Work
}

\begin{abstract}
Purpose: This study seeks to analyze how internal audit functions (IAFs) activities differ, depending on the impact of executive boards and audit committees.

Design/methodology/approach: This study is based on data collected from the Common Body of Knowledge (CBOK) study conducted by the Institute of Internal Auditors Research Foundation in 2010. Using 524 responses from US-Chief audit executives we examine the direct and interaction effects of Audit Committees (ACs) and Executive Boards (EBs) on the probability to perform specific activities with a logistic regression model.
\end{abstract}

Findings: In our manuscript, we show that audit committees and executive boards have different direct and interaction effects on the portfolio of activities performed by the internal audit function. Furthermore, we identified a varying prevalence among activities, which pinpoints to the maturity of IAFs. All findings contribute to the prior and recent discussion about the position of IAFs between the stakeholders audit committee and executive board.

Research limitations/implications: When the CBOK study was designed by the Institute of Internal Auditors, the investigators did not have our research questions in mind. We are therefore limited to those variables that have been collected as part of a larger questionnaire. Nevertheless, our new approach tries to open a new research direction, analyzing different activities performed by IAFs.

Practical implications: The identified portfolio of IAF activities can help practitioners doublecheck their own work and evaluate the impact of the EB and the AC on their activities.

Originality/value: This study provides the first empirical evidence of the influence of ACs and EBs on IAF activities.

Keywords: Internal Audit Function, Executive Board, Audit Committee, Serving Two Masters Paper type: Research Paper 


\section{INTRODUCTION}

As a result of prior experiences from the financial and economic crisis and corporate scandals, the need for effective governance systems that include control and monitoring mechanisms has become more important. The specific roles of the executive board (EB), the audit committee (AC), and the internal audit function (IAF) in monitoring internal control activities have changed in recent years (e.g. Roussy, 2015, 2013; Abbott et al., 2010; Sarens et al., 2009). In addition to the well-known factors of good corporate governance, such as EB and AC members, recent literature increasingly refers to the benefits of implementing an IAF (e.g. Mohamed, 2012) and reiterates that a close collaboration between ACs and the IAF can reduce existing information asymmetries between shareholders and EBs and can therefore improve the overall governance structure (e.g. Abbott \& Parker, 2000; Willekens et al., 2004; Sarens \& De Beelde, 2006; Sarens et al., 2009, 2011; Rizzotti \& Greco, 2013; Zaman \& Sarens, 2013). That is, the IAF is no longer limited to an internal "watchdog" function on behalf of EBs but rather is intended to serve shareholders and other external stakeholder interests, like e.g. the external auditor or regulators, as well (Mohamed, 2012; Abbott \& Parker, 2000; Abbott et al., 2010, 2012).

This development has been spurred by the enactment of the "Sarbanes-Oxley Act of 2002" (SOX). Section 404 of SOX requires the chief executive officer (CEO) and chief financial officer (CFO) of publicly traded U.S. companies to declare that their organizations' internal control systems offer realistic assurance of avoiding material misstatements in financial statements and that ACs' oversight of the corresponding controls and reporting structures is appropriate (Abbott et al., 2010). Although SOX is silent on the IAF's relationship to ACs or EBs, there is a very strong incentive to use the IAF as a supporting instrument for EBs and ACs to ensure the implementation of an adequate internal financial control system, the oversight of internal controls and financial reporting and to create an efficient and effective system of corporate governance (Gramling et al., 2004; IIA, 2013).

In practice, the IAF supports EBs and ACs through the provision of various assurance and consulting activities (Hass et al., 2006; Sarens et al., 2009, 2013; Lenz et al., 2014) and helps the $\mathrm{AC}$ in reducing liability risks. In particular, the IAF is associated with the areas of risk management, internal control systems, financial reporting, and the entire governance process (Abbott et al., 2016; Lenz et al., 2014; Hass et al., 2006). There is a growing body of literature showing positive effects of internal auditing, e.g. in the areas of improved financial reporting (Prawitt et al., 2009, 2012; Abbott et al., 2012, 2016), improved corporate governance (Lenz et al., 2014), better fraud risk assessments and detection (Ege, 2015) and better internal controls 
(Lin et al., 2011).

However, ACs' expectations with respect to IAF activities may be in conflict with the respective EBs' expectations (Abbott et al., 2010; Gray, 2004; Hermanson, 2002; Roussy \& Brivot, 2016). While ACs primarily use the IAF for the assurance of financial statement-related internal controls (Krishnan, 2005; Braiotta, 2000; Reinstein et al., 1984) and as a 'comfort provider' Sarens et al. (2009), EBs rather consider the IAF to be a partner for improving operational processes and for the design and implementation of cost-saving activities (Abbott et al., 2010; Anderson, 2003; Hermanson \& Rittenberg, 2003). As a consequence, the IAF is increasingly supposed to represent the interests of both EBs and ACs, which may lead to imminent problems for the chief auditing executive (CAE) and the IAF as a whole, particularly if the IAF is subject to explicit budget constraints. All potential problems that can occur out of this triangle relationship between the IAF, the $\mathrm{EB}$ and the $\mathrm{AC}$ are often subsumed as a "serving two masters"-problem (STM) from the perspective of the CAE. Furthermore, the strength of the EB and $\mathrm{AC}$ members depends on the quality of the received information from different governance functions and explicitly the IAF (Bedard \& Gendron, 2010; Gendron \& Bedard, 2006). As a result, communication between all three actors, often defined through the reporting process of the IAF, might also be problematic because of the individual goals and objectives (Roussy, 2013, 2015).

While some papers address specific aspects of the relationship between the IAF and ACs or EBs using an experimental, case study or survey approach (e.g. Abbott et al., 2010; Sarens et al., 2009; Hoos et al., 2015), there is no broad empirical evidence with respect to IAF's activities to support the EB and AC. In particular, no evidence on the role and, consequently, the influence of ACs and EBs on IAF activities has been provided thus far. Furthermore, it is unclear whether the influence of EBs on the IAF differs from the influence exerted by ACs and, if so, how this difference affects IAF activities. Based on these insights, we have identified three research questions for our study:

$\mathrm{RQ}_{1}$ : How is the IAF's portfolio of activities typically composed?

$\mathrm{RQ}_{2}$ : Do the $A C$ and the EB influence IAF activities in specific ways, and if so, is there a difference between the influence of the two parties?

$\mathrm{RQ}_{3}$ : How does a simultaneous influence of both, EB and AC, affect IAF activities?

To answer our research questions, we use data from the 2010 Common Body of Knowledge-Study (CBOK) of the IIA. Based on 524 usable responses from the CAEs of U.S. listed companies, we 
use 27 different variables to identify IAF activities and to investigate the consequences of AC's and EB's separated and simultaneous influence on IAF's activities. We use a two-step approach to answer our research questions.

1. In the first step, we examine the activities performed by the IAF in a descriptive way to obtain initial insights $\left(\mathrm{RQ}_{1}\right)$.

2. In the second step, we use a logistic regression model to analyze the direct effects of the roles of the $\mathrm{AC}$ and $\mathrm{EB}$ in the execution of a specific activity $\left(\mathrm{RQ}_{2}\right.$ and $\left.\mathrm{RQ}_{3}\right)$.

Based on these steps, this study contributes to the existing internal auditing literature in three ways. First, it provides new empirical evidence for the determination of IAF activities by ACs and EBs. Second, this study shows how IAF activities as determined by the two parties, i.e., ACs and EBs, relate back to the two parties' responsibilities with respect to the control framework, the oversight of internal controls and financial reporting, and to the creation of an efficient and effective corporate governance system. Third, this work provides further insights into the interplay between ACs and EBs in determining IAF activities, which clearly indicate that potential problems exists. Overall, our study contributes to a better understanding of the role and benefits of the IAF given the regulatory challenges for ACs and boards of directors in the post-SOX era and may therefore also be useful for these involved parties.

The remainder of this paper is structured as follows. Section 2 describes both the IAF literature and the hypothesis development. Section 3 characterizes the data and the sample selection procedure and presents our research design. Section 4 shows the empirical results, and Section 5 concludes the paper. 


\section{THE IAF: PRIOR RESEARCH AND HYPOTHESIS DEVELOPMENT}

This section discusses the IAF (in general) as well as prior research on the relationship between ACs, EBs, and the IAF. Given these insights and the considerable lack of related empirical evidence on the relationship between the AC, the EB, and the IAF, we will develop our hypotheses.

Following the definition of the IIA, the IAF can be defined as follows: "Internal auditing is an independent, objective assurance and consulting activity designed to add value and improve an organization's operations. It helps an organization accomplish its objectives by bringing a systematic, disciplined approach to evaluate and improve the effectiveness of risk management, control, and governance processes." (IIA, 2012) The IAF contributes to the efficiency and effectiveness of companies' processes and controls by conducting reviews of operations and by providing recommendations based on related analyses and evaluations. With commitment to integrity and objectivity, internal auditing provides value to those charged with governance (e.g., ACs, EBs and senior management) as an unbiased source of independent advice. Within its traditional assurance role, the IAF also reviews and tests risk assessment and control activities, two of the major parts of the COSO framework (COSO, 2009), and has an impact on the effectiveness of the monitoring component of this framework. It is important to note that based on the above understanding, the IAF itself is not responsible for implementing and maintaining internal controls or risk management. Rather, the IAF supports the governance actors who are responsible for the implementation and maintenance, i.e., CEOs and CFOs. Furthermore, the IAF can (ex post) identify starting points for the improvement of internal control and risk management efficiency, and IAF's activities are closely related to operational processes and internal control systems on behalf of the EB (Ge \& McVay, 2005; Krishnan, 2005; Verschoor, 2002). The functional sovereignty over the CAE and the day-to-day internal audit process itself is often tied to the $\mathrm{EB}$, while the $\mathrm{AC}$ is responsible for budget constraints and the disciplinary lead. This understanding normally links the majority of IAF's activities to the EB of a company. This role of EBs has the potential to constrain the independence of IAFs. More precisely, the IAF is often subject to the EB's assignment of tasks, such as the selection of units or operations subject to internal audits and the assessment of IAF objectives (Abbott et al., 2010; Anderson, 2003; Hermanson \& Rittenberg, 2003).

Beside this relationship between the IAF and the EB, IAF's link to the ACs has also a special relevance. For instance, Sarens et al. (2009), Gramling \& Hermanson (2006) and McHugh \& 
Raghunandan (1994) show that ACs draw on results from the IAF to meet their own monitoring obligations and to get a necessary level of comfort. An effective AC strengthens the quality of the IAF, and likewise, an effective IAF supports the AC, e.g., in identifying critical developments in the organization as early as possible (Abbott et al., 2010). Especially different quality indicators, like size, know-how, compliance with IIA standards, improve the relationship between the AC and the IAF (Zaman \& Sarens, 2013; Mat Zain et al., 2006). Therefore, the AC "should review and approve the IAF's staffing schedules and financial budgets" (Abbott et al., 2010, p. 2) to ensure the IAF's ability to realize its audit plan. This leads to a positive correlation between the monitoring performed by the AC and the IAF's budget for auditing the internal control system and ultimately to an increase in the quality of the IAF (Abbott et al., 2010; Carcello \& Neal, 2000). Nevertheless, depending on AC's viewpoints of the IAF, based on the work of Roussy \& Brivot (2016) e.g. 'manager', 'watchdog'or 'professional', the specific relationship might be different.

Furthermore, there is evidence for a positive correlation between the IAF's supervision of the financial accounting process, the independence and financial expertise of the AC, and the AC's monitoring of the IAF (Sarens et al., 2013; Mat Zain et al., 2006). According to Abbott et al. (2010) and Carcello et al. (2005), budget control is a key determinant of the relationship between the IAF and the AC, particularly because the supervision performed by the AC and the IAF's budget for auditing the internal control system are positively correlated. These results imply a reinforcing mechanism between the supervision functions of the IAF and ACs in cases where both parties engage in constructive cooperation, as also shown by Goodwin \& Yeo (2001). According to Arena \& Azzone (2009), the effectiveness of the IAF is determined not only by the competences of the IAF and the integration with risk management but also by the degree of cooperation with the AC. It is therefore important that the IAF can also interact with the AC to improve the supervision of management and financial reporting quality (Scarbrough et al., 1998; Goodwin \& Yeo, 2001; Raghunandan et al., 2001; Goodwin, 2003). Moreover, the interplay between ACs and the IAF facilitates the exchange of information and renders data availability more efficient ((Roussy, 2013; BaselCommittee, 2012; Bedard \& Gendron, 2010; Sarens et al., 2009; Scarbrough et al., 1998)).

Finally, the supervision of the IAF by the AC can positively influence the identification of problems within the IAF itself and offers opportunities for further improvement (Zaman \& Sarens, 2013; Bedard \& Gendron, 2010; Arena \& Azzone, 2009). In turn, if the IAF reports directly or indirectly to the AC, its role within the organization is further strengthened, and the 
communication of operational problems to the top levels of the organization is supported (Zaman \& Sarens, 2013; Bedard \& Gendron, 2010; Arena \& Azzone, 2009; Goodwin \& Yeo, 2001). In sum, ACs usually have a substantial interest in having an effective IAF to support their own monitoring activities (Bedard \& Gendron, 2010; Sarens et al., 2009; Gendron \& Bedard, 2006), to enhance the quality of financial reporting (Mohamed, 2012; Prawitt et al., 2009, 2012), and to meet the additional legal requirements with respect to the IAF (particularly with respect to financial misstatements) e.g. as introduced by SOX (Abbott et al., 2010; Beasley et al., 2009; Abbott \& Parker, 2000).

With respect to SOX, the IAF-related incentives of ACs can further be differentiated into three dimensions. First, financial misstatements lead to reputational detraction of the AC member (Anderson et al., 2012; Beasley, 1996; Srinivasan, 2005). Second, financial misstatements significantly increase the risk of liability (Carcello \& Neal, 2000; Abbott \& Parker, 2000). Third, SOX directly relates to internal financial controls and the prevention of material control weaknesses (Coffee, 2005). Therefore, ACs in general have an incentive to maximize IAF effort focused on internal controls (Anderson et al., 2012). The second and third dimensions are linked to the improvement of the overall corporate governance quality of a company and should therefore be in the interests of all corporate governance parties in general. Although this fact sounds suitable for both, ACs and EBs, EBs are normally facing a performance-related remuneration scheme, and are likely to consider whether the value added from additional IAF effort related to internal controls will be greater than the potential cost savings derived from additional IAF efforts focusing on improvements in operational processes (Gray, 2004; Anderson, 2003; Abbott et al., 2010). Because of direct influence of the EB on the CAE and the internal audit process, the objectives of an executive board-focused IAF work may affect the CAE more intensively and directly as the AC perspective. Thus, either intentionally or unintentionally, the EB has some type of power and dominance over the auditors' work, which potentially constrains the independence of the IAF. More precisely, the IAF is subject to EB's assignment of tasks, i.e., which units or operations to audit and evaluate.

There is some empirical evidence that both EB and ACs have an incentive to influence the IAF's activities (Carcello \& Neal, 2000; Gramling et al., 2004). As a consequence, direct access or reporting lines between the $\mathrm{AC}$ and the IAF have gained considerable importance over the last decade. Not surprisingly, closer relationships between the AC and the IAF can essentially lead to a potential conflict with the EB, which, because of its financial incentives, do not necessarily regard the IAF primarily as a critical monitoring body but also view it as an assistant providing 
advisory services linked to operational processes (Gray, 2004; Anderson, 2003; Hermanson \& Rittenberg, 2003).

In particular, conflicts of interest can also result from IAF's reporting lines to the EB and the AC. In addition, although direct reporting from the IAF to the AC can have a positive impact on the IAF's independence and impartiality (Cohen et al., 2004), it can also create latent mistrust to the communication line to the EB and impair the provision of necessary information by the EB or management to the IAF. Another potential conflict may arise from EBs' functional sovereignty over the CAE, who would simultaneously face the AC's authority to review and approve the annual audit plan, to release IAF's budget and to evaluate CAE's work.

The relationship of the CAE and the whole IAF to their main stakeholders, AC and EB, is strongly influenced by the direct and indirect reporting lines to the executive board and audit committee. Depending on the initiator of formal or informal reporting routines, the position of the IAF varies (Zaman \& Sarens, 2013). E.g. an effective AC can only be achieved, if the communication to different governance functions is well established and all information that matters is shared directly. Especially, while prior literature identifies informal communication to the IAF outside of formal meetings as a key success factor (Bedard \& Gendron, 2010; Gendron \& Bedard, 2006; Beasley et al., 2009; Sarens et al., 2013; Turley \& Zaman, 2007). But strong communicational ties to one stakeholder may affect the other as well. In other words, a too strong relation to the $\mathrm{EB}$ might be a problem for the $\mathrm{AC}$ and vice versa.

With respect to the differences between the AC's and EBs' incentives, two different strands of IAF activities can be identified. The first strand links the IAF directly to the traditional role of a "watchdog" with a strong focus on control-oriented activities. This setting allows the AC to preferentially determine IAF activities. The second strand uses the IAF for the continuous improvement of processes and procedures to contribute to the value added in the companyspecific value chain. In this setting, the IAF is directly linked to the EB. The organizational position of the IAF as well as the corresponding IAF activities can be assumed to be determined by company characteristics and the regulatory framework.

The IIA standards also describe the position of the IAF between different stakeholders in front of the IAF's activities. IIA Performance Standard 2000 "Managing the Internal Audit Activity" requires the following: "The chief audit executive must effectively manage the internal audit activity to ensure it adds value to the organization" (IIA, 2012). Therefore, the CAE together with the EB and AC is responsible for establishing internal audit activity that assesses and improves effectiveness of governance, risk management, and control processes. Because it is 
impossible to examine a large number of personal relationships between CAEs and the AC or $\mathrm{EB}$, the activities performed by the IAF can be used as a good proxy to analyze the influence of the two players on the IAF and all activities that are performed by the IAF.

Based on this prior research and our focus on the dilemma of the IAF between the EB and the AC, we identify three major hypotheses for our study.

$\mathbf{H}_{1}$ : The more influence the EB has on the IAF, the more likely the IAF is to perform activities prioritized by the EB, c.p.

$\mathbf{H}_{2}$ : The more influence the AC has on the IAF, the more likely the IAF is to perform activities prioritized by the AC, c.p.

Assuming that a problem for the IAF in the relationship to the AC and EB actually exists, we expect the IAF's portfolio of activities to be subject to the importance of the EB and the AC. Furthermore, given that the IAF (at least in the short term) should usually also be subject to budgetary constraints, we also expect potential conflicts of interests between the EB and AC to lead to crowding out IAF activities that do not serve their own interest. Consequently, our third hypothesis is as follows:

$\mathbf{H}_{3}$ : If the influence of the $E B$ and the $A C$ is equally strong, then the IAF is less likely to perform an activity to serve either the $E B$ or the $A C$.

We conceptualize the existence of an "serving two masters" constellation as the simultaneous occurrence of an equally strong role of both the EB and the AC.

Figure 2 shows four example graphs representing different constellations of the role of the EB and the role of the AC. The upper left part depicts the IAF's likelihood to perform an activity if only Hypothesis 1 held true. The upper right part displays the same scenario for the AC as presented in Hypothesis 2. The lower right part illustrates the nature of a negative interaction effect as formulated in Hypothesis 3. In contrast, the lower left part shows what a positive interaction would look like, i.e., a complementary effect.

\section{[FIGURE 1 HERE]}

The resulting conceptual model consists of two main effects and one interaction effect, as shown in Figure 2. This model is meant to hold for all IAF activities.

[FIGURE 2 HERE] 


\section{RESEARCH DESIGN}

\section{Data and sample selection}

To empirically test our conceptual model, we rely on secondary data. Our empirical analysis is based on the 2010 "Common Body of Knowledge" (CBOK) database, the most comprehensive global research base on the practice of internal auditing. The research conducted and validated by the Institute of Internal Auditors Research Foundation (IIARF) concerns current knowledge in internal auditing worldwide as well as current and future audit activities, IIA standards, and core competencies of internal auditors. The CBOK study contains data from more than 107 countries and more than 13,500 useful survey responses. The survey includes answers from CAEs, internal audit service providers, and internal audit staff. However, we include only responses from CAEs to obtain a single evaluation of the status of an IAF. This results in a total of $\mathrm{n}=$ 2,795 CAE responses worldwide. Furthermore, we use only firms under U.S. regulation, such that regulation serves as a blocking factor. Our final sample therefore consists of 524 responses. ${ }^{1}$ The 524 observations represent a broad spectrum of industries and sizes for U.S.-listed companies.

The size of the dataset has favorable consequences for the level of statistical power. First, because of the large number of different observations, a broad variety of specific companies is given. Therefore, our sample has a high level of representativeness and enables the generalizibility of our results for this unique framework of U.S.-listed companies. With the use of data from only one country, further country-specific effects can be eliminated.

\section{Analytical approach}

The analytical approach consists of three elements. First, the descriptive analysis gives initial insights regarding the data characteristics and helps to show the typical activities performed by the IAF. Second, we operationalize the influence of the EB and the AC as well as the presence of a simultaneous influence. Third, we test the hypotheses by using a set of logistic regressions.

The following analysis is conducted using IBM SPSS 22. The descriptive analysis sheds light on the composition of the sample as well as the distribution of variables. We focus on the absolute and relative frequencies of the categorical variables and the measures of location and dispersion for the metric variables.

The operationalization relates to the auxiliary theories linking the observed variables to our focal constructs. The explanandum in our study is the IAF's portfolio of activities. Our dataset

\footnotetext{
${ }^{1}$ Although this approach seems to exclude typical two-tier board system, e.g. like Germany or Austria, the position of the IAF between the EB and a supervisory board is comparable to the position of the IAF between the EB and the AC.
} 
contains information about 25 discrete activities that are either performed by the IAF or not. All activities are coded as dichotomous variables for which a value of 1 signifies that the IAF in the observed firms performs this activity and a value of 0 signifies that the IAF does not perform this activity. Our conceptual framework contains three explanatory variables:

1. The role of the EB is our first explanatory variable and can vary in strength; its value can range from weak to strong. The concept is thus of a continuous nature. However, the strength of the role of the EB is not directly observable, which makes it a latent variable. Based on the corresponding questions in the CBOK questionnaire, we create a linear combination of two indicator variables as a proxy for the latent variable (Rigdon, 2012):

- The first indicator variable has a value of "1" if the report on internal controls is signed by the CEO or the CFO and a value "0" otherwise.

- The second indicator variable has a value "1" if the audit plan is established upon request from the management and a value "0" otherwise.

2. The role of the $\mathrm{AC}$ is our second explanatory variable. Analogous to the role of the EB, the strength of the role of the AC is also regarded as a latent variable. Again, based on the CBOK questionnaire, we create a linear combination of two indicator variables as a proxy for the latent variable:

- The first indicator variable has a value "1" if the report on internal controls is signed by the chairman of the board or the chairman of the $\mathrm{AC}$ and a value "0" otherwise.

- The second indicator variable has a value "1" if the audit plan is established upon $\mathrm{AC}$ requests and a value "0" otherwise.

3. The third explanatory term in the conceptual model captures the simultaneous influence of $\mathrm{AC}$ and $\mathrm{EB}$ and can be understood as a STM-constellation. It has become common practice to equate the simultaneous occurrence of events with their multiplicative interaction (Gibson \& Birkinshaw, 2004). Modeling interactions as the product of two independent variables is also recommended from a statistical perspective (Aiken \& West, 1991; Jaccard \& Turrisi, 2003). We therefore operationalize this concept as the interaction of the strength of EB's role and the strength of AC's role. Specifically, we create an interaction term as a multiplicative composition. To avoid problems of multicollinearity and to facilitate interpretation, we orthogonalize the interaction term (Lance, 1988). 
The following Table 1 depicts the different variables in our model and the possible values for the dependent and indicator variables as well as the model used.

\section{[INSERT TABLE 1 HERE]}

The hypothesis tests involve the multivariate effects of the quasi-continuous proxies on internal audit activities, which serve as dichotomous dependent variables. We apply a set of logistic regressions to estimate the parameters of the structural model for each of the IAF's activities. Logistic regression is used to estimate the following model for each of the 25 activities:

$$
\begin{aligned}
& \operatorname{logit}\left(\mathrm{ACTIVITY}_{i}\right)=\beta_{0}+\beta_{1} \cdot \mathrm{AC}+\beta_{2} \cdot \mathrm{EB}+\beta_{3} \cdot \mathrm{AC} \times \mathrm{EB}+\zeta \\
& \text { Predicted Signs: } \quad(+) \quad(+) \quad(-)
\end{aligned}
$$

Moreover, we included a set of control variables to reduce omitted variable bias and avoid interpretational confounding: the number of employees, the total assets in $\$ \mathrm{US}$, the total revenue or budget, and a dummy variable indicating whether the firm provides financial services. To maintain the study-wide error rate, it is important to use an alpha level for each logistic regression analysis that is stricter than the classical 5-percent level. We therefore suggest using a Bonferroni correction (Rice, 1989). Although the Bonferroni correction is known to be a rather conservative correction (Cabin \& Mitchell, 2000), we regard it as adequate for our study because of the high statistical power resulting from the rather large sample size. 


\section{RESULTS}

\section{Descriptive analysis}

The relevance and reputation of the organization's IAF positively reflect the number and quality of activities performed by the IAF. Therefore, in the CBOK study, the respondents were asked to select those activities that reflect the type of tasks they perform with their IAF out of a list of 25 different activities. The CBOK survey participants indicated which types of activities they perform and rank them from the most to the least selected activity. Therefore, our descriptive analysis examines internal audit activities to provide a better understanding of the different types of activities that are expected from an IAF by its different stakeholders. Furthermore, the descriptive results highlight the importance of the main internal audit activities. In particular, the descriptive analysis presents results of the CBOK survey related to the current scope of internal audit activities.

Figure 3 depicts the relative frequency of the IAF's activities in descending order. While some activities (e.g., "Operational audits" or "Auditing of financial risks") are performed by almost all firms, other activities (e.g., the implementation of Extensible Business Reporting Language (XBRL) or migration to International Financial Reporting Standards (IFRS)) are performed by only a small fraction of companies. There is a relatively clear distinction between the 12 activities that are performed by the majority of the firms (more than 50.0 percent of our sample perform these specific activities) and the remaining 13 activities that are performed by the minority of the firms.

\section{[INSERT FIGURE 3 HERE]}

The activity with the highest value in our sample is "Operational Audits", which is performed by 92.7 percent of all IAFs. It is not surprising that the examination of an operating unit or the evaluation of a process, as measured by management's objectives, is one of the typical activities performed by an IAF. With this work, an IAF should be compliant with the given standards and add value through their findings to different stakeholders (like the AC and the EB). The second activity "Auditing of financial risks" with a value of 86.6 percent can be seen as a typical IAF activity. Creating reliable financial reporting processes and minimizing financial risks assure a company's sustainable financial development and provides evidence of the quality of the board's work. "Investigations of fraud and irregularities" (83.0 percent) help an organization to address its risk of fraud and create a trustful environment for the internal and external addressees of financial reporting. A good working IAF recognizes potential fraud and therewith the potential 
reputational risks of a company. Especially because of the technological developments in recent decades, the role of the IAF as a specialist for detecting IT/ICT risks has expanded. This can also be seen as a possible explanation for the value of 75.4 percent for the activity "Auditing of IT/ICT risks".

Through the implementation of the COSO framework, the IAF is often considered one of the "four pillars" of good corporate governance, in addition to the board of directors, management, and the external auditor. Therefore, "Evaluating the effectiveness of control systems" is a major activity for 75.0 percent of IAFs. After different corporate scandals that were caused by compliance irregularities, compliance with regulatory codes, for example, is a central part of good corporate governance. Hence, the IAF often tests and reports on whether an organization is in compliance with the requirements of various laws, regulations, contracts, and agreements. For 71.6 percent of the respondents, "Audit of compliance" is a typical activity of their IAF. In addition to IT and ITC risks, companies currently face different information risks. The IAF can also audit these types of risks, and it does so in 67.9 percent of the sample companies. A close relationship between the IAF and the external auditor can improve the efficiency and effectiveness of the entire audit processes. Of course, the IAF can assist the external auditor in minimizing extra (audit) work, as it does for 66.8 percent of the U.S.-listed companies from our sample. "Security Assessments and Investigations" is an activity that depends especially on directives from management, boards, and ACs, where internal auditors should play an assurance and investigative role in organization security processes and structures. In our sample, 61.8 percent of the firms perform this activity with their IAF.

Companies have numerous projects every day with different strategic and operative objectives. Furthermore, the volume of a typical project can easily reach hundreds of millions of U.S. dollars. For this reason, it might be helpful for internal auditors to continuously audit and support major projects to minimize the potential costs. In our sample, 58.8 percent of the IAFs regularly audit "Major projects" and provide project management assurance. However, it is not only the project management that is a possible auditing object. The management itself or any type of managerial activities can also be audited by the IAF. The IAF tries to independently examine organizational structures and processes as well as strategic and operative plans with the goal of evaluating the level of achievement or performance of managerial tasks or management teams. In our sample, 55.0 percent audit "Management" to ensure that all objectives are achieved. The last of the twelve activities is "Disaster recovery testing and support" and is performed by more than the half of IAFs ( 52.9 percent). The IAF can play a crucial role 
in planning, testing, and evaluating the disaster recovery plan to help a company survive and return to business as usual.

The twelve presented activities are performed by more than half of our sample companies, while the following activities are performed by a lower proportion of companies. These more specific activities include "Corporate Governance Reviews" (41.0 percent) and "Ethic Audits" (35.7 percent) as well as very specific actions such as "Going-Concern Assessments" (13.9 percent) and "Implementation of Extensible Business Reporting Language (XBRL)" (5.9 percent). None of the last 13 activities appear to be especially relevant to the typical day-to-day business of an IAF.

Overall, this large variety of different activities performed by the IAFs require the IAFs to adapt and strengthen their specific skills to accept new challenges. These specific requirements will also have an impact on the type and nature of the relationship with the $\mathrm{AC}$ and the $\mathrm{EB}$ as well as internal consequences such as hiring new staff and will also, of course, affect the IAF's portfolio of activities.

\section{Hypothesis test}

Based on the descriptive results, we test our hypothesis with a logistic regression model for every activity. Table 2 shows the results of the different logistic regressions. For every activity (item), the $\beta$ and the $p$-value are given for the three different explanators "AC", "EB", and "AC $\times \mathrm{EB}$ ". Furthermore, Nagelkerke's $R^{2}\left(\right.$ abbr. $\left.R_{N}^{2}\right)$ as a pseudo- $R^{2}$ statistic shows that whereas some activities can be substantially explained by our framework, such as "Migration to International Financial Reporting Standards" $\left(R_{N}^{2}=0.151\right)$ or "Evaluating Effectiveness of Control Systems" $\left(R_{N}^{2}=0.149\right)$, there are other activities that are hardly explainable, such as "Business Viability (Going-concern) Assessments" $\left(R_{N}^{2}=0.020\right)$ or "Audits of Enterprise Risk Management Processes" $\left(R_{N}^{2}=0.022\right)$. Overall, we can confirm that our model is able to partly explain why a firm's IAF does or does not perform a certain activity. In the first step, we analyze the overall results for the three different explanators:

1. We find a significant positive single effect of the AC's role in the IAF's portfolio of activities for $\mathbf{1 2}$ out of $\mathbf{2 5}$ activities.

2. We find a significant positive single effect of the EB's role in the IAF's portfolio of activities for $\mathbf{9}$ out of $\mathbf{2 5}$ activities.

3. We find a significant negative interaction effect for $\mathbf{3}$ out of $\mathbf{2 5}$ activities, which means 
that we find empirical evidence that the presence of an STM constellation has a negative effect on the IAF's portfolio of activities.

First, these results show that both governance players, the $\mathrm{AC}$ and the $\mathrm{EB}$, have a positive significant effect on the activities performed by an IAF. Overall, 19 different activities from the full portfolio of 25 activities are significantly affected. Fifteen out of these 19 activities are affected by only one player ("AC" or "EB" or "AC $\times \mathrm{EB}$ ").

Furthermore, there are three activities for which our results show significant (negative) interaction effects, i.e., crowding-out effects with respect to these activities. To analyze our results in more detail, it is interesting to see how many different activities are affected.

More specifically, the results for the twelve activities that are performed by the majority of companies as well as the thirteen activities that are performed by the minority of companies in our dataset are helpful for understanding the underlying mechanisms. Table 2 summarizes the results for the three models. First, four out of the top twelve activities are not affected by any direct or interaction effect. These four activities are as follows:

1. Operational audits

2. Investigation of fraud and irregularities

3. Project management assurance/audits of major projects

4. Disaster recovery testing and support

\section{[INSERT TABLE 2 HERE]}

Apart from the finding that none of the four activities show a significant impact from either of the two governance parties, there are crucial distinctions. While "Operational audits" and "Investigation of fraud and irregularities" are performed by more than 80 percent of all IAFs, the activities "Project management assurance/audits of major projects" and "Disaster recovery testing and support" are respectively performed by only 58 and 52 percent of the sample. As mentioned above, the investigation of fraud and the audit of a company's operations are key activities of an IAF and are performed irrespective of the role and potential impact of the EB or the AC. This might explain why there is no statistically significant effect of the role of these parties on performing these activities.

Similarly, project-related assurance services or disaster-related activities can be assumed to be generally initiated by the IAF itself. The activity "Auditing of financial risks" is only affected by the EB. This finding is likely observed because it is the EB that is primarily responsible for the 
going-concern opinion of the company, whereas the respective responsibility of the $\mathrm{AC}$ is limited to monitoring. Moreover, according to SOX Sec. 302, the CEO is particularly responsible and liable for financial statements and consequently for the appropriate description of going-concern opinions, while the $\mathrm{AC}$ has oversight of the EB and can punish the EB (e.g., through termination of the CEO's contract). Especially because of SOX and different types of certifications and subcertifications, this result seems reasonable: the CEO has to sign and guarantee the quality of financial reports.

Likewise, compared with the AC, the EB is much more affected by "Auditing of IT/ICT risks" and should therefore have a stronger incentive to initiate IT/ITC audits.

The activity "External Audit Assistance" is positively influenced by the EB. The presumed direct effect here would be a significant positive effect from the AC. A possible explanation for the missing effect is that the $\mathrm{AC}$ has to work with the external auditor and does not want to rely too strongly on the internal auditing work from the external auditors' perspective. There are also some empirical papers that focus on this relationship and potential negative effects on audit quality (e.g., Mihret \& Admassu, 2011). A possible motivation for the EB to support the relationship between internal and external audit is that the results obtained by external auditors could be better or that audit fees are minimized along with the costs for the company. In addition, "External Audit Assistance" is affected by the EB. Although this result is questionable from a practical perspective, it is highly reasonable because statutory (external) auditors may obtain direct assistance from internal auditors under certain circumstances. In these cases, the external auditor usually addresses the EB to facilitate related practical issues, i.e., it should also be the EB that initiates related IAF activities.

From a principal-agent perspective, management audits could be an effective way for the $\mathrm{AC}$ to reduce information asymmetries and to minimize the moral hazard of managers. This explains the significant positive influence of the AC, but the EB has no significant influence.

The direction of the effects for the activities "Audits of compliance with regulatory code requirements" and "Auditing of information risks" are the same for the AC and EB: the effects are significant and positive. For both players, these activities could be crucial ways to reduce a company's risk and to improve the overall governance construct.

Furthermore, we have three different activities with an interaction effect. The first is the activity "Evaluating the effectiveness of control systems". First, we try to explain the direct effects. For both the AC and the EB, a good working internal control framework can improve overall governance quality. This should be the reason for both parties to influence the IAF 
to perform this type of activity. Furthermore, from a regulatory perspective, good working internal controls are necessary because of various SOX requirements. The significant negative interaction effect could point to "STM effects". The occurrence of an STM constellation is negatively associated with the likelihood of performing the activity "Evaluating the effectiveness of control systems". This could be an indicator of coordination problems because of a dualistic influence of $\mathrm{AC}$ and $\mathrm{EB}$ on the IAF. The understanding or objectives of the evaluation through the IAF may also differ between AC and EB. Nevertheless, the task of evaluating the effectiveness of control systems is usually performed outside of the IAF by the external auditor.

Two other activities have a significant negative interaction effect: "Business viability (goingconcern) assessments" and "Quality/ISO audits". Although the AC and the EB do not both have direct significant effects, the interaction effect is (negatively) significant.

Compared to the activity "Evaluating effectiveness of control systems", the results are not identical. Only the AC has a significant direct effect for the activity "Quality/ISO audits". However, if both stakeholders, the $\mathrm{AC}$ and the $\mathrm{EB}$, use their influence on the IAF, the interaction effect is significant (negatively), such that the likelihood if performing this activity is lower. Quality/ISO audits are also normally performed outside of the IAF by specialized quality/ISO auditors. The activity "Business validity assessments (going concern)" does not have a significant direct effect from the $\mathrm{AC}$ or the $\mathrm{EB}$, but a significant interaction effect is observed. The likelihood of performing this activity is also lower if the $\mathrm{AC}$ and the $\mathrm{EB}$ influence the work of the IAF. The external auditor usually assesses business validity and gives a going-concern opinion.

Interestingly, all three negative interaction effects are significant if an activity is normally or can possibly be outsourced or if there is also a regulatory need for this activity to be performed by others. The evaluation of internal controls and the business validity assessment are both typical work tasks of the external auditor, while quality and ISO audits are typically performed by "Certified quality audit agencies", not by the IAF.

If these three activities should be performed by the IAF because of the influence of the AC and the EB, the likelihood that the IAF will perform these three activities is lower.

This situation may lead to an "STM phenomenom" and may support our hypothesis $\mathrm{H}_{3}$. If both the AC and the EB try to influence the IAF to perform a specific activity, the CAE must react and serve two masters simultaneously. However, for activities that can or must be done by external entities as well, the CAE attempts to avoid having a problematic situation between two masters. Furthermore, the IAF will not perform a specific activity, and this activity might be performed by external entities. 
Overall, we can summarize our results as follows:

- Based on the significant positive single effect of the EB's role in the IAF's portfolio of activities for 9 out of 25 activities, Hypothesis $\mathrm{H}_{1}$ is confirmed.

- Based on the significant positive single effect of the AC's role in the IAF's portfolio of activities for 12 out of 25 activities, Hypothesis $\mathrm{H}_{2}$ is also confirmed.

- Based on the significant negative moderating effect for 3 out of 25 activities, which means that we find empirical evidence that the $\mathrm{EB}$ and the $\mathrm{AC}$ have a joint negative effect on the IAF's portfolio of activities, Hypothesis $\mathrm{H}_{3}$ is confirmed.

- The predicted and observed signs for the direct effects of the AC and EB are positive, while the predicted and observed sign for the interaction effects in our model is negative, with this interaction indicating a lower probability of performing an activity. 


\section{DISCUSSION}

The position of the IAF between the EB and the AC is often described as the "STM problem" in the literature. In particular, the simultaneous impact of both governance bodies on the activities of the IAF has not been empirically tested in previous research. Hence, this paper analyzes the direct effects of the $\mathrm{EB}$ and the $\mathrm{AC}$ on the activities of the IAF. We also include an interaction effect to identify potential differences or similarities in the AC's or EB's impact on different activities, thereby revealing potential "STM problems".

This first and, to our knowledge, only approach to empirically test the impact of the EB and the $\mathrm{AC}$ on the portfolio of activities performed by the IAF generated different relevant results. Our descriptive results show that some IAF activities are performed from the majority of all IAFs and some are performed by only a few IAFs. Although this result seems trivial, this characterization of the portfolio of activities performed by the IAF can be seen as a first step to analyze the direct and interaction effects of the EB and/or AC on these activities. The realized activities are used as a proxy for the concrete input of the different players.

Our logistic regression model shows that different activities are significantly influenced by the AC or the EB. Furthermore, some activities are not significantly influenced by direct or interaction effects and are therefore independent from the role of the $\mathrm{AC}$ or the EB. Moreover, some activities are significantly influenced by the interaction of the AC and EB.

The overview of significant effects for the activities performed by the IAF also shows that "typical IAF activities", such as operational audits or audits of financial risks, are not influenced by the $\mathrm{AC}$ or $\mathrm{EB}$ or by their joint effort.

The portfolio of IAF activities can thus be characterized as follows:

- There are activities performed by a large majority of the sample companies and activities performed by only some companies.

- There are some activities that are influenced positively (and significantly) by either the $\mathrm{AC}$ or the EB.

- There are some activities that are influenced positively (and significantly) by both the AC and the EB, without one interfering with the other.

- There are some activities that are influenced negatively (and significantly) by the presence of an STM constellation (i.e., the interaction of the AC and EB).

For those three activities with a negative interaction effect, we provide a graphical representation of the corresponding activity. Figure 4 depicts the likelihood that the IAF performs the activity 
"Business viability (going-concern) assessments", whereas Figure 5 illustrates the likelihood that the IAF performs the activity "Quality/ISO audits". Both figures clearly demonstrate that the activity has the highest likelihood of being performed if either the $\mathrm{AC}$ or the EB play a strong role, but not both simultaneously. Interestingly, the likelihood of performing the two activities in case of an STM constellation is not higher than the likelihood in a situation in which both the EB and AC play only a weak role. Finally, Figure 6 shows the likelihood that the IAF performs the activity "Evaluating effectiveness of control systems (using COSO, COBIT, etc. frameworks)". This activity shows a completely different situation, particularly because the likelihood of performing this activity is high in general. The negative interaction effect could represent a dominating effect: it is sufficient if one party (either the AC or the ED) stimulates this activity; additional stimulation by the other party does have a negative effect.

\section{[INSERT FIGURE 4 HERE]}

\section{[INSERT FIGURE 5 HERE]}

\section{[INSERT FIGURE 6 HERE]}

In addition to the statistical interpretation, we also discuss the practical and theoretical implications of our results in more detail. In particular, the results for the activity "Evaluating the effectiveness of control systems" are very interesting. The negative interaction effect points to a negative relationship between the impact of the $\mathrm{AC}$ and the EB. We interpret this as an indicator of coordination problems between the AC and $\mathrm{EB}$ in terms of effects on the IAF with respect to the question of whether this activity should be performed or not. In our model, the probability of performing the activity is significantly higher if the $\mathrm{AC}$ or the $\mathrm{EB}$ use their own possible (i.e., individual) influence. However, if both use their influence simultaneously, the interaction leads to a significantly negative effect. The following is one possible interpretation of this result: given that the external auditor also has to audit the internal control system as part of the statutory audit, the IAF rather delegates respective activities and thus attempts to conserve resources and avoid conflicts.

A similar argument can be applied to the activity "Going-Concern Assessment". According to AU Sec 341, the Auditor's Assessment of the Going-Concern Assumption is mandatory. As part of obtaining sufficient appropriate evidence, the auditor may-under certain circumstancesrely on the work done by the IAF or even obtain direct assistance from the IAF. In other words, there are specific audit procedures that may be conducted by the auditor or the IAF. Based on our evidence, we conclude that with respect to these procedures, an STM situation exists. 
In other words, the IAF chooses not to conduct these procedures if both the EB and AC play strong roles.

A similar situation is given by the International Organization for Standardization (ISO). ISO allows only third-party certification bodies to provide independent confirmation that an organization meets the requirements of a specific ISO or quality standard. The quality/ISO audit must be performed by other external entities as well, such that there is no need for the IAF to perform this activity and serve both masters simultaneously.

All significant negative interaction effects can also show the option of the IAF to rely on the external evaluation and conserve its own resources and thus to reduce potential conflicts between the IAF and the stakeholders AC and EB.

In summary, all three IAF activities that show an interaction effect with respect to the impact of the $\mathrm{EB}$ or the $\mathrm{AC}$ can relatively easy be delegated to an external party-or not and instead be assumed as an additional task instead of leaving it to an external supplier in the first place. This finding suggests that in these cases, potential conflicts of interest between the EB and the AC that may arise for the IAF when both parties play a strong role are mitigated by outsourcing IAF activities to external parties. In other words, given budgetary restrictions (which are quite common, as the literature has shown), rather than cannibalizing individual tasks that are not in the common interest of the $\mathrm{EB}$ and the $\mathrm{AC}$ and not conducting activity at all, the IAF is rather prone to delegating activities if appropriate in such situations. This is particularly the case for activities that usually involve external parties.

From a practical perspective, our results help to understand and improve the current IAF arrangement in a company. Although we do not include further information about the specific companies, our tested effects serve as an initial basis for the discussion in every organizational context, no matter what type of industry or company size. Based on the corporate characteristics and the corporate culture, the specific arrangement of IAF activities and the objectives of the $\mathrm{EB}$ and $\mathrm{AC}$ will vary. E.g. companies with a strong compliance focus and industry-specific regulation will have a stronger focus on assurance related activities, while others will force a consulting role of the IAF. Furthermore, the discussion about the implementation of new governance frameworks, like the Three-Lines-of-Defense-Model, might directly or indirectly affect the concrete arrangement of the AC, the EB and the IAF and IAF's performed activities. 


\section{Implications for the IAF and future research}

In our model, we used dependent variables (activities performed by the IAF) with either direct or interactive independent variables (influence of the $\mathrm{AC}$, influence of the $\mathrm{EB}$ and influences from an interaction effect). The results can lead to a situation in which the IAF must "serve two masters". Because of the interests and power of the two different stakeholders-the AC and the EB-the probability of performing an activity by the IAF is affected, which leads, ceteris paribus, to a resource allocation problem. Especially the cases where the probability is influenced significantly by only one stakeholder, "additional activities" must be covered by the IAF.

Based on our approach, our results support the research questions only if there are different effects of the $\mathrm{AC}$ and $\mathrm{EB}$ on the IAF and if there is a interaction effect that will influence the probability of performing an activity. We can say something about the direct or interaction effects of the AC and EB on the IAF's portfolio of activities and, hence, the possible activity performed; however, we can not identify a concrete "problem" for the IAF through our model or data set.

In general, resource allocation is a process whereby an organization or function in an organization determines how to apportion its resources among the various potential activities in which it aims to engage. For the IAF, resource allocation is the plan for using the available (human) resources to achieve the goals given by its stakeholders. More specifically, the IAF can allocate its scarce time and auditors among the various potential audits. To create a priority ranking of audits, the IAF or the CAE must plan the use of the given resources based on the needs of the $\mathrm{AC}$ and the EB. If both stakeholders, the $\mathrm{AC}$ and the $\mathrm{EB}$, use their possible influence to lead the IAF to perform a specific activity, ceteris paribus, the CAE must decide what to do (or what to audit). This leads to a situation in which the CAE is in a position between the AC and EB. The CAE will try not to enforce the disagreement between the "Masters" and the "Servant" and will attempt to escape the situation with minimal harm. This situation might affect the personnel situation of the CAE as well.

This "STM situation" seems to consist of three different categories:

1. The allocation of the IAF's resources

2. The CAE's position between two active and powerful stakeholders

3. The impact on the IAF's activities

Of course, our approach has some limitations that should be further explained here. First, there are some limitations because of the dataset used. When the CBOK study was designed 
by the Institute of Internal Auditors, the investigators did not have our research questions in mind. We are therefore limited to those variables that have been collected as part of a larger questionnaire. Second, most of the respondents are members of the national IIA chapters and may be biased toward evaluating their own work and the influence of the AC or the EB. Third, the independent variables used are not directly observable and have been substituted by proxies created from two different manifest variables. Furthermore, our focus on U.S.-listed companies excludes all types of regulatory or country-specific influences. Although this approach can also be seen as an advantage, the level of generalizibility for other countries or regulatory environments might be limited. For instance, are these results also true for companies from European countries or U.S. non-listed companies? The position between the EB and the supervisory board in twotier board systems might be comparable to the EB-AC-relationship in the one-tier-board model. Although our logistic regression model is conceptualized in a straightforward manner, one could argue that other factors influencing the probability of performing an activity as an IAF are not included. There might be other potential independent variables or control variables that could be included. E.g. the quality of the IAF is a potential research perspective, which could be used to extend our approach and model, because the quality might affect the monitoring behavior and the usage of the IAF also. Based on these limitations and open questions, there are various possibilities for future research. In addition to the inclusion of data from other countries or regulatory frameworks, additional variables from the CBOK dataset could be included. These results can testify as to whether the structure of the AC's and EB's impact on the IAF in performing a specific activity are the same or different. It could also be very interesting to analyze the patterns and structure of the activities performed in more detail. Are there specific portfolios of activities that are performed by the IAF? Do these portfolios of activities further affect the $\mathrm{AC}$ or $\mathrm{EB}$ or vice versa?

Nevertheless, the given results show that the activities performed by the IAF are influenced by the AC and the EB in different ways. Furthermore, the presence of an STM constellation reduces the likelihood of some specific activities. Although there is an "STM effect", this does not necessarily imply an "STM problem". This could be a good starting point for future research and other (perhaps experimental) research approaches. 


\section{References}

Abbott, L., \& Parker, S. (2000). Audit committee characteristics and auditor choice. Auditing: A Journal of Practice and Theory, 19(2), 47-66.

Abbott, L., Parker, S., \& Peters, G. F. (2010). Serving two masters: The association between audit committee internal audit oversight and internal audit activities. Accounting Horizons, $24(1), 1-24$

Abbott, L. J., Daughtery, B., Parker, S., \& Peters, G. F. (2016). Internal audit quality and financial reporting quality: The joint importance of independence and competence. Journal of Accounting Research, 54(1), 3-40.

Abbott, L. J., Parker, S., \& Peters, G. F. (2012). Internal audit assistance and external audit timeliness. Auditing: A Journal of Practice \&3 Theory, 31, 3-20.

Aiken, L. S., \& West, S. G. (1991). Multiple regression: Testing and interpreting interactions. THousand Oaks, CA: Sage.

Anderson, U. (2003). Research opportunities in internal auditing, chapter 4: Assurance and consulting services. IIA Research Foundation Report.

Anderson, U., Christ, C. H., Johnstone, K. M., \& Rittenberg, L. E. (2012). A post-sox examination of factors associated with the size of internal audit functions. Accounting Horizons, 26, 167-191.

Arena, M., \& Azzone, G. (2009). Internal audit effectiveness: Relevant drivers of auditees satisfaction. International Journal of Auditing, 13(1), 43-60.

BaselCommittee (2012). The internal audit function in banks. Bank for International Settlements.

Beasley, M. S. (1996). An empirical analysis of the relation between the board of director composition and financial statement fraud. The Accounting Review, 71(4), 443-465.

Beasley, M. S., Carcello, J. V., Hermanson, D. R., \& Neal, T. (2009). The audit committee oversight process. Contemporary Accounting Research, 26(1), 65-122.

Bedard, J., \& Gendron, Y. (2010). Strengthening the financial reporting system: Can audit committees deliver? International Journal of Auditing, 14, 174-210. 
Braiotta, L. J. (2000). The Audit Committee Handbook. John Wiley, 2nd ed.

Cabin, R. J., \& Mitchell, R. J. (2000). To bonferroni or not to bonferroni: when and how are the questions. Bulletin of the Ecological Society of America, 81(3), 246-248.

Carcello, J. V., Hermanson, D. R., \& Raghunandan, K. (2005). Changes in internal auditing during the time of the major us accounting scandals. International Journal of Auditing, 9(2), 117-127.

Carcello, J. V., \& Neal, T. L. (2000). Audit committee composition and auditor reporting. The Accounting Review, 75 (10), 453-467.

Coffee, J., J.C. (2005). The scarlet letter: What happens after an adverse opinion on internal controls? The Corporate Governance Advisor, 13(1), 1-6.

Cohen, J., Krishnamoorthy, G., \& Wright, A. (2004). The corporate governance mosaic and financial reporting quality. Journal of Accounting Literature, 23, 87-152.

COSO (2009). Guidance on monitoring internal control systems. Committee of Sponsoring Organizations of the Treadway Commission.

Ege, M. (2015). Does internal audit function quality deter management misconduct? The Accounting Review, 90, 495-527.

Ge, W., \& McVay, S. (2005). The disclosure of material weaknesses in internal control after the sarbanes-oxley-act. Accounting Horizons, 19(3), 137-158.

Gendron, Y., \& Bedard, J. (2006). On the constitution of audit committee effectiveness. Accounting, Organizations and Society, 31(3), 211-239.

Gibson, C. B., \& Birkinshaw, J. (2004). The antecedents, consequences, and mediating role of organizational ambidexterity. Academy of management Journal, 47(2), 209-226.

Goodwin, J. (2003). The relationship between the audit committee and the internal audit function: Evidence from australia and new zealand. International Journal of Auditing, 7(3), $263-278$

Goodwin, J., \& Yeo, T. (2001). Two factors affecting internal audit independence and objectivity: evidence from singapore. International Journal of Auditing, 5(2), 107-125.

Gramling, A., \& Hermanson, D. (2006). Corporate governance - what role is your internal audit function playing? Internal Auditing, 6, 37-39. 
Gramling, A., Maletta, A., Schneider, A., \& Church, B. (2004). The role of the internal audit function in corporate governance: A synthesis of the extant internal auditing literature and directions for future research. Journal of Accounting Literature, 23, 194-244.

Gray, G. (2004). Exploring the effects of the sarbanes-oxley act on internal auditors. Working paper, California State University.

Hass, S., Abdolmohammadi, M. J., \& Burnaby, P. (2006). The americas literature review on internal auditing. Managerial Auditing Journal, 21(8), 835-844.

Hermanson, D., \& Rittenberg, L. (2003). The growing stature of internal auditing. Internal Auditing, 17(6), 43-44.

Hermanson, D. R. (2002). The growing stature of internal auditing. Internal Auditing, 17(6), $43-44$.

Hoos, F., Kochetova-Kozloski, N., \& d'Arcy, A. C. (2015). The importance of the chief audit executive's communication: Experimental evidence on internal auditors' judgments in a 'two masters setting'. International Journal of Auditing, 19(3), 166-181.

IIA (2012). International standards for the professional practive of internal auditing (standards). The Institute of Internal Auditors.

IIA (2013). The three lines of defense in effective risk management and control. The Institute of Internal Auditors.

Jaccard, J., \& Turrisi, R. (2003). Interaction effects in multiple regression. 72. Thousand Oaks, CA: Sage.

Krishnan, J. (2005). Audit committee quality and internal control: An empirical analysis. The Accounting Review, 80(2), 649-675.

Lance, C. E. (1988). Residual centering, exploratory and confirmatory moderator analysis, and decomposition of effects in path models containing interactions. Applied Psychological Measurement, 12(2), 163-175.

Lenz, R., Sarens, G., \& D'Silva, K. E. (2014). Probing the discriminatory power of characteristics of internal audit functions: Sorting the wheat from the chaff. International Journal of Auditing, 18, 126-138. 
Lin, S., Pizzini, M., Vargus, M., \& Bardhan, I. R. (2011). The role of the internal audit function in the disclosure of material weaknesses. The Accounting Review, 86(1), 287-323.

Mat Zain, M., Subramaniam, N., \& Stewart, J. (2006). Internal auditors' assessment of their contribution to financial statement audits. the relation with audit committee and internal audit function characteristics. International Journal of Auditing, 10(1), 1-18.

McHugh, J., \& Raghunandan, K. (1994). Internal auditor' independence and interactions with audit ccommittee: challenges of form and substance. Advances in Accounting, 12, 313-333.

Mihret, D., \& Admassu, M. (2011). Reliance of external audit on internal audit work: A corporate governance perspective. International Business Research, 4(2), 67-79.

Mohamed, Z. (2012). The age of internal audit function and internal audit's contribution to financial statement audit: Implications on audit fees. The Journal of American Academy of Business, 18(2), 303-311.

Prawitt, D. F., Sharp, N. Y., \& Wood, D. A. (2012). Internal audit outsourcing and the risk of misleading or fraudulent financial reporting: Did sarbanes-oxley get it wrong? Contemporary Accounting Research, 29, 1109-1136.

Prawitt, D. F., Smith, J. L., \& Wood, D. A. (2009). Internal audit quality and earnings management. The Accounting Review, 84(4), 1255-1280.

Raghunandan, K., Read, W., \& Rama, D. (2001). Audit committee composition, 'gray directors" and interaction with internal auditing. Accounting Horizons, 15, 108-118.

Reinstein, A., Callaghan, J., \& Braiotta, L. J. (1984). Corporate audit committees: Reducing directors' legal liabilities. Journal of Urban Law, (61), 375-389.

Rice, W. R. (1989). Analyzing tables of statistical tests. Evolution, 43(1), 223-225.

Rigdon, E. E. (2012). Rethinking partial least squares path modeling: in praise of simple methods. Long Range Planning, 45(5), 341-358.

Rizzotti, D., \& Greco, A. (2013). Determinants of board of statutory auaudit and internal control committee diligence: A comparison between audit committee and the corresponding italian committees. The International Journal of Accounting, 48(1), 84-110.

Roussy, M. (2013). Internal auditors roles: From watchdogs to helpers and protectors of the top manager. Critical Perspectives on Accounting, 24(7/8), 550-571. 
Roussy, M. (2015). Welcome to the day-to-day of internal auditors: How do they cope with conflicts? Auditing: A Journal of Practice and Theory, 34(2), 237-264.

Roussy, M., \& Brivot, M. (2016). Internal audit quality: a polysemous notion? Accounting, Auditing \& Accountability Journal, 29(5), 714-738.

Sarens, G., Allegrini, M., D’Onza, G., \& Melville, R. (2011). Are internal auditing practices related to the age of the internal audit function?: Exploratory evidence and directions for future research. Managerial Auditing Journal, 26(1), 51-64.

Sarens, G., Christopher, J., \& Zaman, M. (2013). A study of the informal interactions between audit committees and internal auditors in australia. Australian Accounting Review, 23(4), $307-329$

Sarens, G., \& De Beelde, I. (2006). The relationship between internal audit and senior management: an analysis of expectations and perceptions. International Journal of Auditing, 10(3), 219-241.

Sarens, G., De Beelde, I., \& Everaert, P. (2009). Internal audit - a comfort provider to the audit committee. British Accounting Review, 41(2), 90-106.

Scarbrough, D., Rama, D., \& Raghunandan, K. (1998). Audit committee composition and interaction with internal auditing: Canadian evidence. Accounting Horizons, 12(1), 51-62.

Srinivasan, S. (2005). Consequences of financial reporting failures for outside directors: Evidence from re-statements. Journal of Accounting Research, 43(2), 291-334.

Turley, S., \& Zaman, M. (2007). Audit committee effectiveness: Informal processes and behavioural effects. Accounting, Auditing \& Accountability Journal, 20(5), 765-788.

Verschoor, C. (2002). Reflections on the audit committee's role. The Internal Auditor, 59(2), $26-35$

Willekens, M., Vander Bauwhede, H., \& Gaeremynck, A. (2004). Voluntary audit committee formation and practices among belgian listed companies. International Journal of Auditing, $8,207-222$.

Zaman, M., \& Sarens, G. (2013). Informal interactions between audit committees and internal audit functions: Exploratory evidence and directions for future research. Managerial Auditing Journal, 28(6), 495-515. 


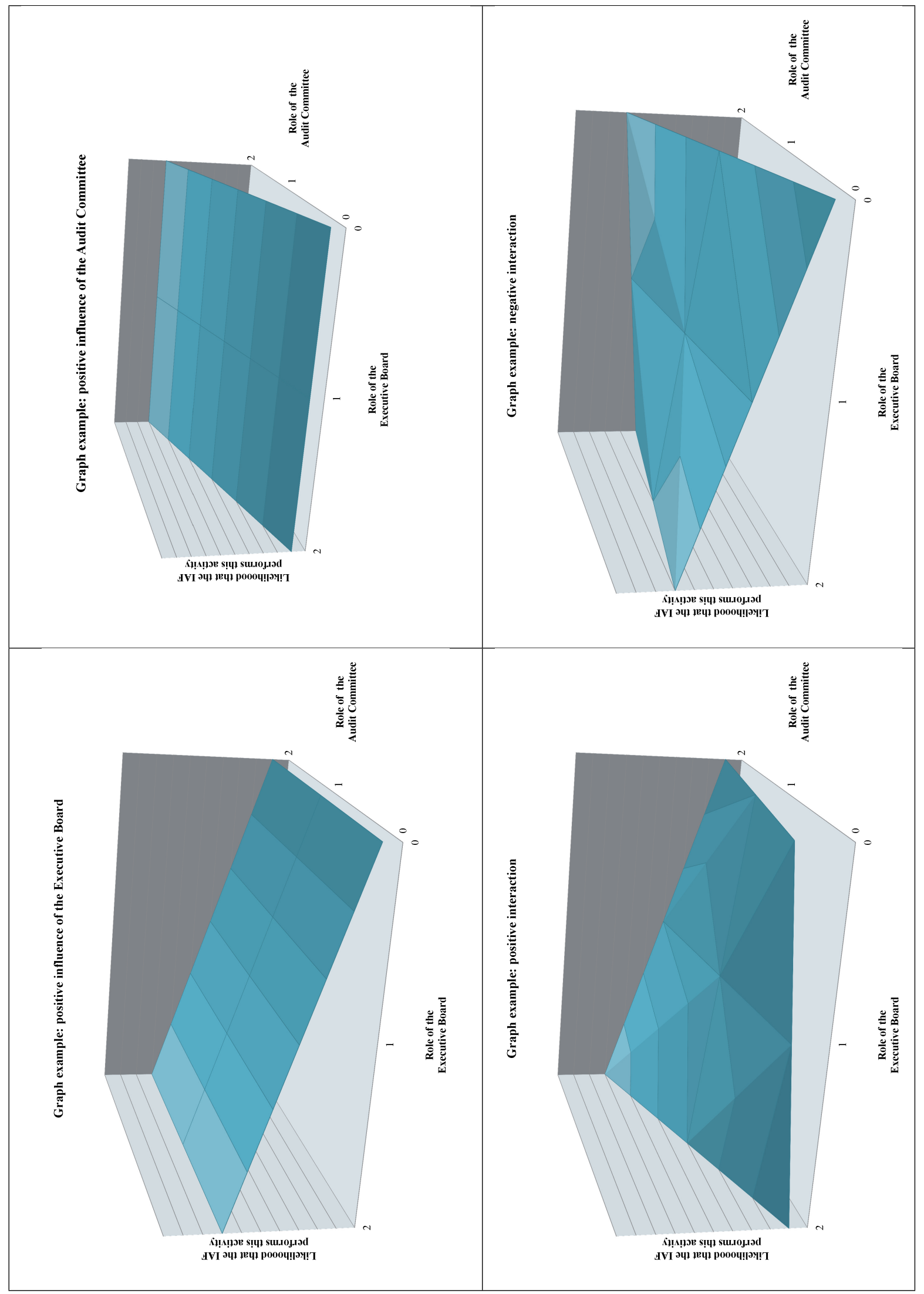

Figure 1: Graph examples for four different anticipated results 


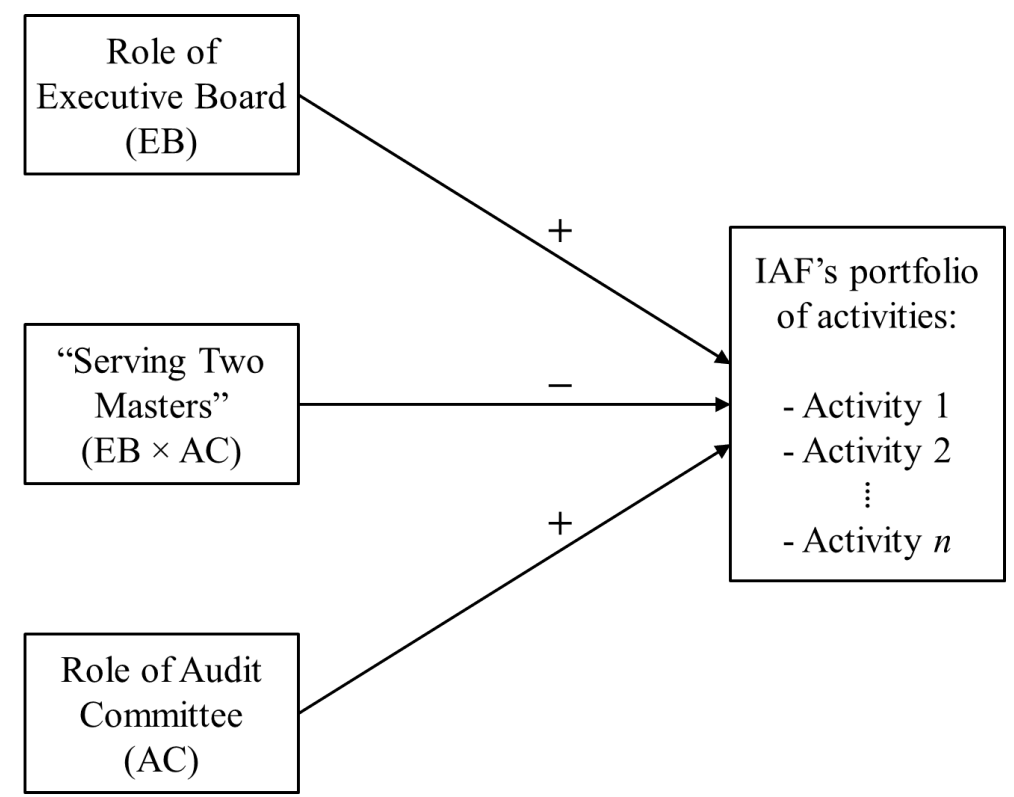

Figure 2: Conceptual Framework 


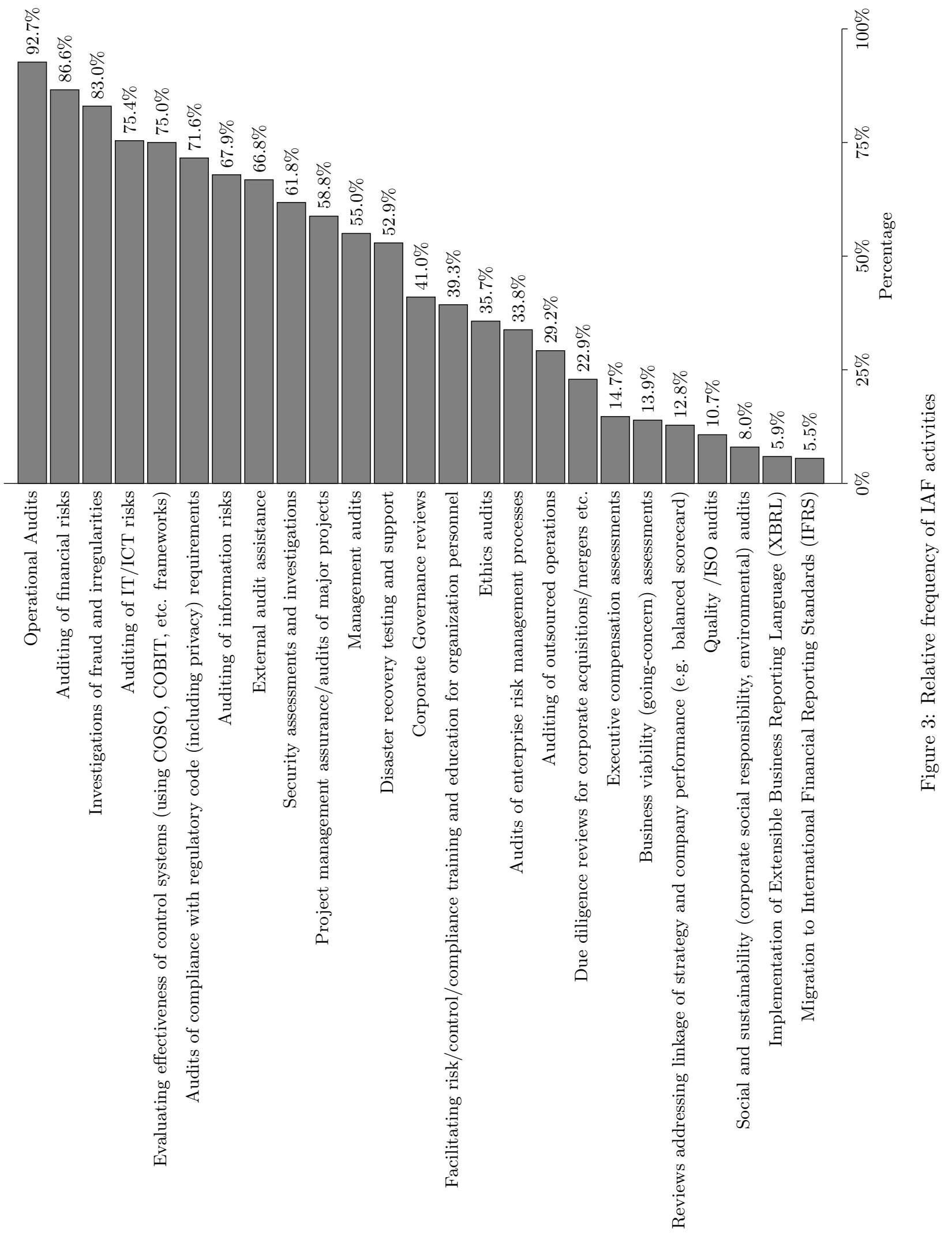




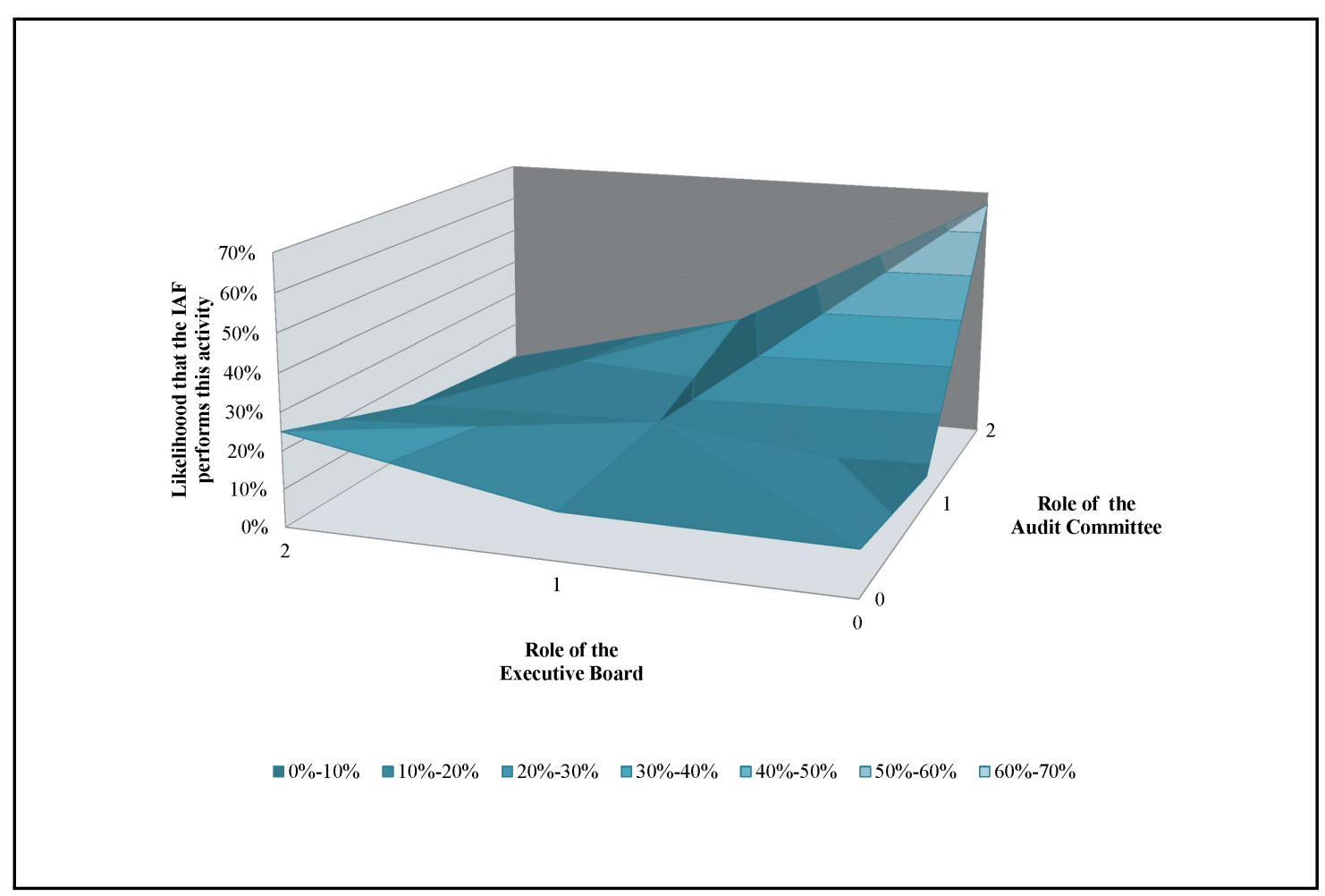

Figure 4: Likelihood that the IAF performs the activity "Business viability (going-concern) assessments" 


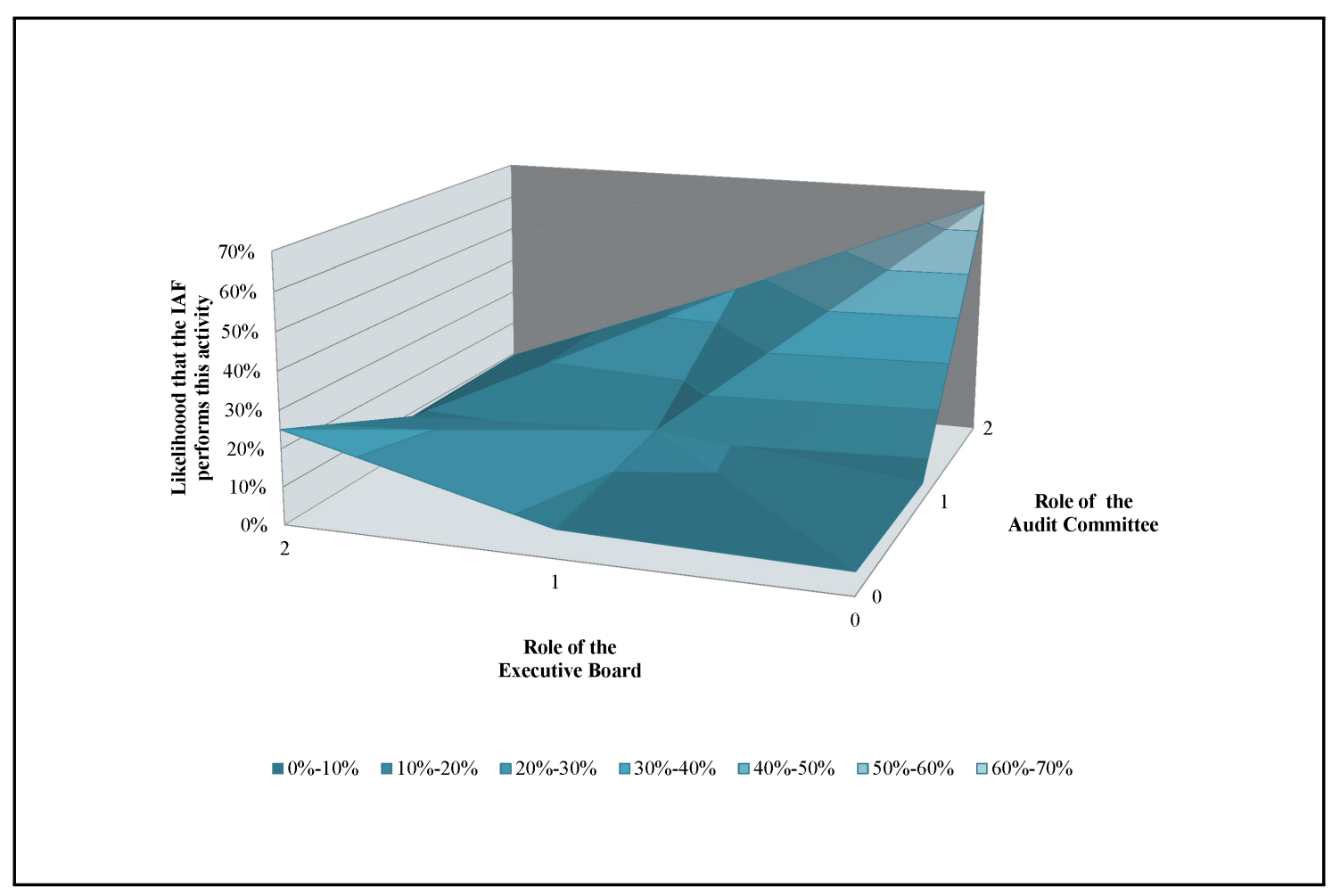

Figure 5: Likelihood that the IAF performs the activity "Quality/ISO audits" 


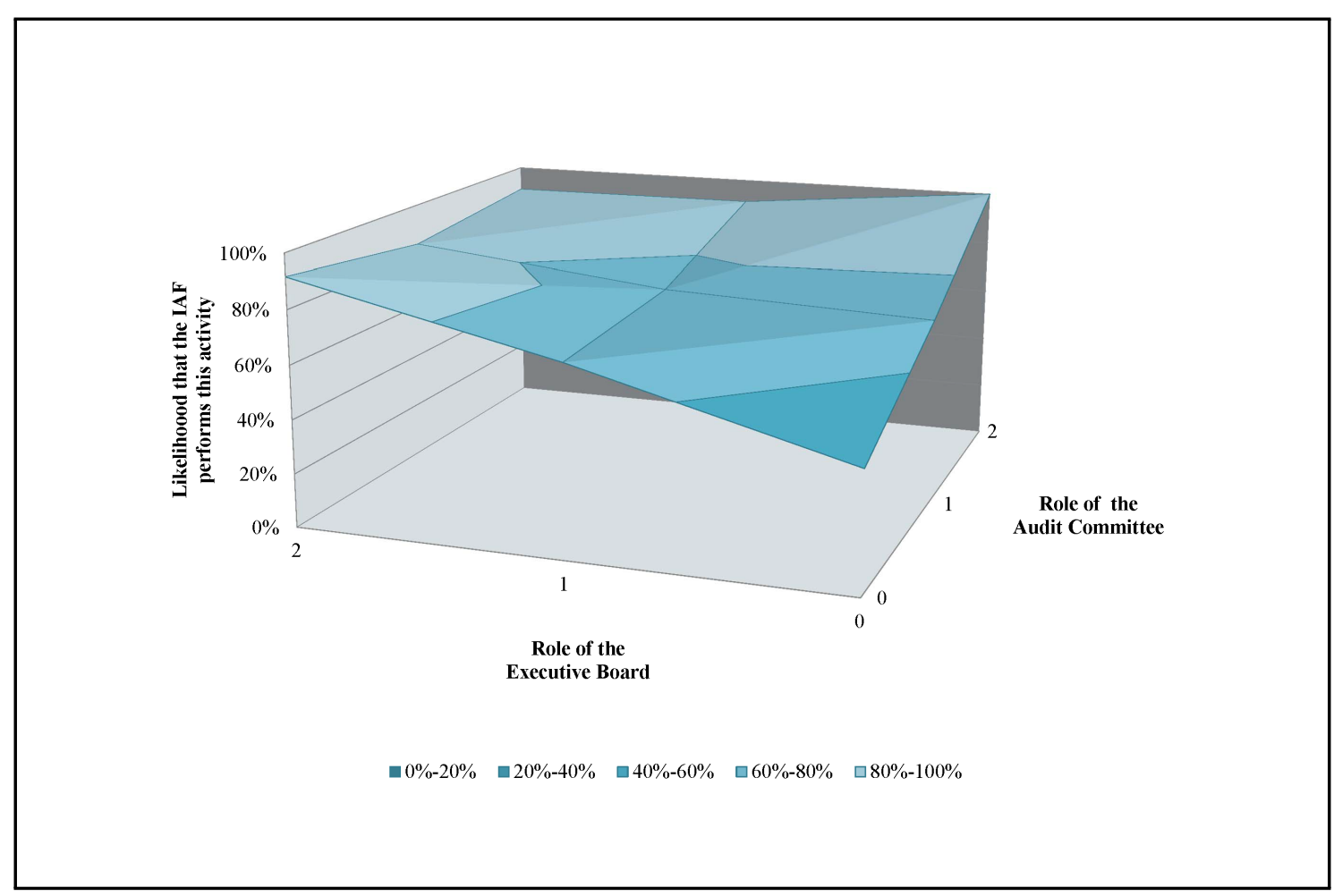

Figure 6: Likelihood that the IAF performs the activity "Evaluating effectiveness of control systems (using COSO, COBIT, etc. frameworks)" 


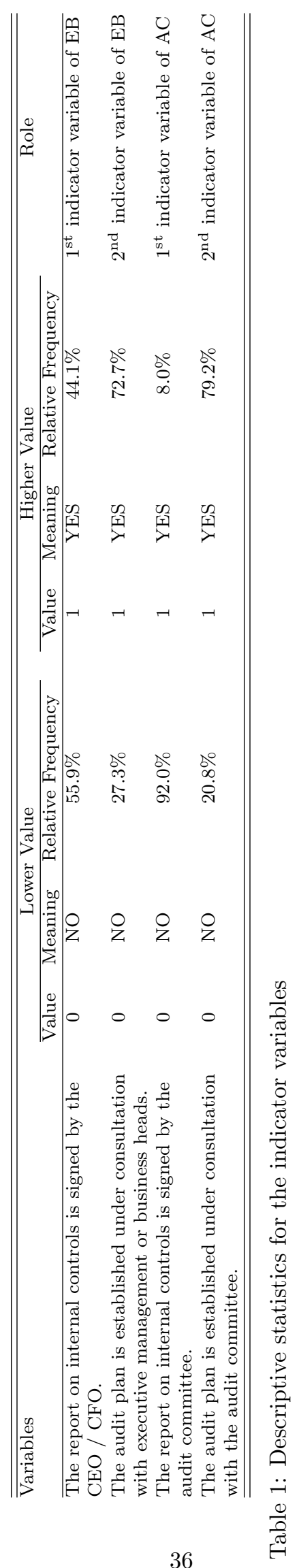




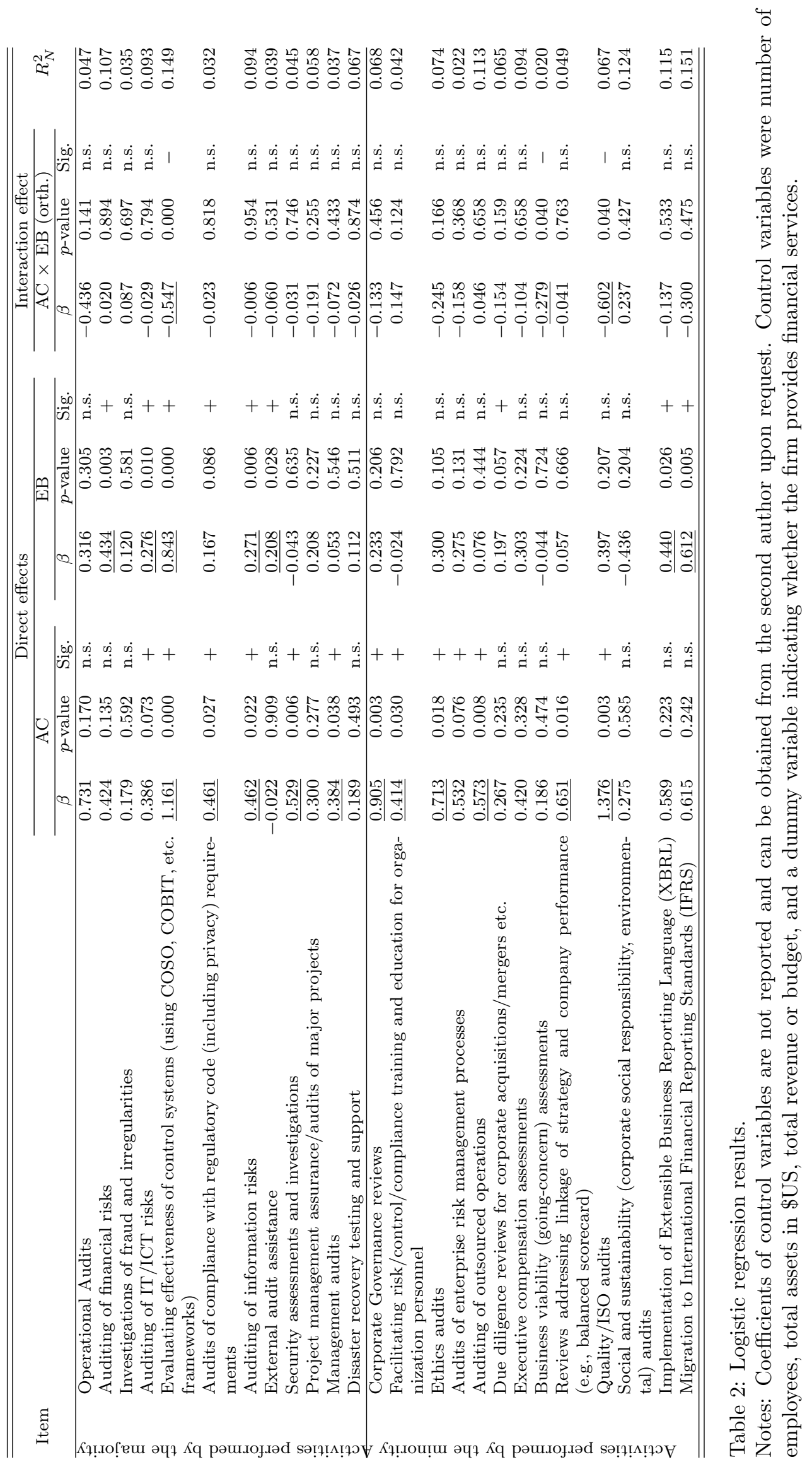



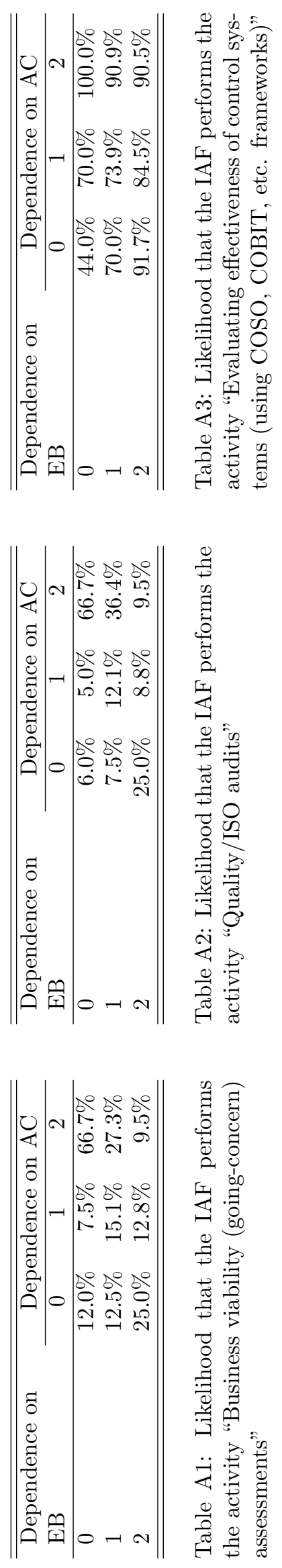